Published in final edited form as:

Acta Mater. 2015 September 1; 96: 66-71. doi:10.1016/j.actamat.2015.06.013.

\title{
Kinetic analysis of $\mathrm{MgB}_{2}$ layer formation in advanced internal magnesium infiltration (AIMI) processed $\mathrm{MgB}_{2}$ wires
}

\author{
G. Z. Li ${ }^{*}$, M. D. Sumption, and E. W. Collings \\ Center for Superconducting and Magnetic Materials (CSMM), Department of Materials Science \\ and Engineering, The Ohio State University Columbus, OH 43210 USA
}

\begin{abstract}
Significantly enhanced critical current density $\left(J_{\mathrm{c}}\right)$ for $\mathrm{MgB}_{2}$ superconducting wires can be obtained following the advanced internal Mg infiltration (AIMI) route. But unless suitable precautions are taken, the AIMI-processed $\mathrm{MgB}_{2}$ wires will exhibit incomplete $\mathrm{MgB}_{2}$ layer formation, i.e. reduced superconductor core size and hence suppressed current-carrying capability.

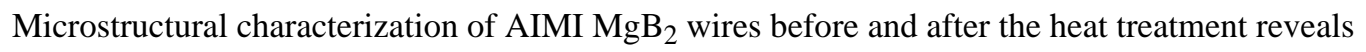
that the reaction mechanism changes from a "Mg infiltration-reaction" at the beginning of the heat treatment to a "Mg diffusion-reaction" once a dense $\mathrm{MgB}_{2}$ layer is formed. A drastic drop in the $\mathrm{Mg}$ transport rate from infiltration to diffusion causes the termination of the $\mathrm{MgB}_{2}$ core growth. To quantify this process, a two-stage kinetic model is built to describe the $\mathrm{MgB}_{2}$ layer formation and growth. The derived kinetic model and the associated experimental observations indicate that fully reacted AIMI-processed $\mathrm{MgB}_{2}$ wires can be achieved following the optimization of $\mathrm{B}$ particle size, $\mathrm{B}$ powder packing density, $\mathrm{MgB}_{2}$ reaction activation energy and its response to the additions of dopants.
\end{abstract}

\section{Keywords}

Magnesium diboride; AIMI; infiltration; kinetics; electron microscopy

\section{Introduction}

$\mathrm{MgB}_{2}$ with its medium critical temperature $\left(T_{\mathrm{c}}=39 \mathrm{~K}\right)$, inexpensive raw materials and round multifilament form [1] is very suitable for practical superconducting wires. Over the past decade, the performance of $\mathrm{MgB}_{2}$ has been remarkably improved [2-6], which resulted in commercially available, long-length $\mathrm{MgB}_{2}$ superconducting wires [7, 8] used in magnetic resonance imagers [9] and wind turbine generators[10]. However, the conventional $\mathrm{MgB}_{2}$ wires, fabricated by the powder-in-tube (PIT) method, generally suffer from "high porosity and weak intergranular connectivity" [11,12]. As a result, it is extremely difficult to achieve the critical current density $\left(J_{\mathrm{c}}\right)$ needed for applications that require working temperatures around $20 \mathrm{~K}$ and magnetic fields of 5-10 T.

*Corresponding author. 1i.1423@ osu.edu (G. Z. Li). 
Recent research has demonstrated that the infiltration process is effective in producing dense and well-connected $\mathrm{MgB}_{2}$ with $J_{\mathrm{c}} \mathrm{s}$ of over $1.0 \times 10^{5} \mathrm{~A} \mathrm{~cm}^{-2}$ at $4.2 \mathrm{~K}$ and $10 \mathrm{~T}$ [13-16], much higher than those of typical PIT $\mathrm{MgB}_{2}$ conductors. In preparation for the infiltration process, a $\mathrm{Mg}$ rod placed along the axis of a metal tube is surrounded by B powder. During heat treatment the $\mathrm{Mg}$ melts and infiltrates into the $\mathrm{B}$ preform. Because of the volume expansion that accompanies the $\mathrm{B} \rightarrow \mathrm{MgB}_{2}$ reaction, voids in the initial $\mathrm{B}$ preform are entirely filled. Consequently, a fully dense cylinder of $\mathrm{MgB}_{2}$ replaces the initial B preform. Although this method produces high-quality $\mathrm{MgB}_{2}$ with superior layer- $J_{\mathrm{c}}$, it has been found that the $\mathrm{MgB}_{2}$ layer growth stops shortly after the onset of the heat treatment, leaving an unreacted B shell, and a less-then-optimal engineering current density $J_{\mathrm{e}}$ (i.e. critical current over whole strand area) $[14,17]$. Recent advances by our group have led to an empirical understanding of the limiting layer thickness effect, and have allowed us to modify wire geometry/design, precursor choice, and heat treatment conditions to minimize this effect [18]. Our advanced internal Mg infiltration (AIMI) wire design achieves complete reaction of an infiltration based composite, resulting in not only a high layer- $J_{\mathrm{c}}$ but also an enlarged $\mathrm{MgB}_{2}$ cross-sectional area hence increased $\mathrm{MgB}_{2}$ fill factor and $J_{\mathrm{e}}$. Nonetheless, our knowledge of the mechanism of $\mathrm{MgB}_{2}$ layer formation was far from adequate to overcome the experimental difficulties encountered in the development of AIMI wires. For example, while $\mathrm{C}$ doping proved to be the most effective way to enhance the layer- $J_{c}$, it suppressed the $\mathrm{MgB}_{2}$ layer growth at the same time. So a heavily C-doped AIMI wire ended up with a poorly reacted conductor with high layer- $J_{\mathrm{c}}$ but low $\mathrm{MgB}_{2}$ fill factor and low $J_{\mathrm{e}}$ [19]. Therefore, to further develop the infiltration-processed $\mathrm{MgB}_{2}$ wire it became necessary to investigate the kinetics of the $\mathrm{B} \rightarrow \mathrm{MgB}_{2}$ formation process during the heat treatment and to identify the variables that control $\mathrm{MgB}_{2}$ formation.

The microstructural evolution in the AIMI-processed $\mathrm{MgB}_{2}$ wires before and after the heat treatment was examined by scanning electron microscopy (SEM) and transmission electron microscopy (TEM). The microscopic observations showed that a dense $\mathrm{MgB}_{2}$ layer is formed in the place of initial B precursor layer shortly after the onset of heat treatment. The $\mathrm{Mg}$ transport mechanism changes from reactive infiltration through $\mathrm{B}$ at the beginning, to diffusion through $\mathrm{MgB}_{2}$ into the remaining unreacted $\mathrm{B}$ once the initial layer is formed-a much slower process. A two-stage model has been developed to describe this kinetic process, one that perfectly explains the experimental observations and provides suggestions for future AIMI wire development.

\section{Experimental}

The microstructural evolution of a previously reported AIMI-processed $\mathrm{MgB}_{2}$ wire [18] was characterized. The wire was $0.83 \mathrm{~mm}$ in outer diameter, consisted of a $\mathrm{Mg}$ rod positioned along the axis of a B-filled double tube of $\mathrm{Nb}$ (the chemical barrier) and Monel® (the hard outer sheath). Nano-sized B powders from Specialty Materials Inc, pre-doped with 2 mol. \% $\mathrm{C}$ enabled an enhancement of the pinning strength and an increase in the upper critical field $B_{\mathrm{c} 2}[5,20]$. A segment of the filled-and-drawn wire was encapsulated in a quartz tube under $\mathrm{Ar}$, and reacted at $675^{\circ} \mathrm{C}$ for $1 \mathrm{~h}$ at which point, according to previous research [18], we expected the $\mathrm{MgB}_{2}$ layer growth to stop. For comparison purposes, another segment removed from the as-drawn wire prior to the heat treatment was cold pressed by a home- 
made pressing machine under a horizontal load of $32.5 \mathrm{kN}$ and a vertical load of $68.5 \mathrm{kN}$, deforming its cross-section from circular $(0.83 \mathrm{~mm}$ diameter $)$ to rectangular $(0.94 \times 0.65$ $\left.\mathrm{mm}^{2}\right)$.

Microstructures were studied by a FEI Sirion FEG SEM, and a FEI/Philips CM-200T TEM with $\mathrm{LaB}_{6}$ cathode. The TEM samples were prepared by a FEI Helios NanoLab 600 DualDeam focused ion beam (FIB) equipment.

\section{Results and Discussion}

\subsection{Microstructural evolution}

The microstructural evolution in the AIMI-processed $\mathrm{MgB}_{2}$ wires before and after the heat treatment has been investigated using SEM and TEM. Fig. 1(a) shows the fracture crosssection of the unreacted AIMI wire. The $\mathrm{Mg}$, located in the wire center, is surrounded by an annular layer of $\mathrm{B}$. Once heated above $650{ }^{\circ} \mathrm{C}$, the $\mathrm{Mg}$ melts and reactively infiltrates the $\mathrm{B}$ preform, transforming $\mathrm{B}$ into $\mathrm{MgB}_{2}$. Fig. 1(b) shows the $\mathrm{B}$ precursor layer as being composed of randomly-packed $B$ spheres whose sizes are $10-120 \mathrm{~nm}$ and $60 \mathrm{~nm}$ on average [21]. According to Scott et al. [22], the maximum packing density for randomly packed spheres is around $64 \%$. So as seen in Fig. 1(b) a large quantity of dispersed nano-sized voids exists amid the $\mathrm{B}$ particles and acts as capillary network for $\mathrm{Mg}$ infiltration. The formation of $\mathrm{MgB}_{2}$ quickly consumes the $\mathrm{Mg}$ leaving behind a central hole. Fig. 2(a) and Fig. 2(b) show the cylindrical core that replaces the B preform during heat treatment at $675^{\circ} \mathrm{C}$ for 1 h. Detailed SEM analysis reveals the microstructural change along the cross-sectional radius of the cylinder, from a dense layer (Fig. 2(c)) to a transition region (Fig. 2(d)) and eventually to a porous layer (Fig. 2(e)). The dense layer located at the very inner side contains almost no porosity (Fig. 2(c)). Energy dispersive spectroscopy (EDS) analysis identifies the composition of this layer as $\mathrm{MgB}_{2}$, so we also refer it as " $\mathrm{MgB}_{2}$ layer". It is this region in the wire that provides the superconductivity. Outside the $\mathrm{MgB}_{2}$ layer is a transition region as well as a surrounding porous layer. The porous layer itself is enclosed, as shown in Fig. 2(e), by an outer region, in this case mainly composed of nano-sized B spheres (indicating incomplete $\mathrm{MgB}_{2}$ formation) positioned close to the outer surface of the cylinder. This last layer, close to the outer cylinder is the "unreacted B layer". In addition, the "transition region" between the "unreacted B layer" and the " $\mathrm{MgB}_{2}$ layer", indicates a microstructural evolution from the porous B-rich structure to dense $\mathrm{MgB}_{2}$. As displayed in Fig. 2(d), dense bulk phases are gradually formed when B particles react with $\mathrm{Mg}$ and coalesce with each other. However, given its weak connectivity, this transition region is unable to contribute significantly to the transport $J_{\mathrm{c}}$.

The $\mathrm{MgB}_{2}$ layer and the partially-reacted transition region were also examined by TEM. Fig. 3(a) shows the microstructure in " $\mathrm{MgB}_{2}$ layer", whose platelet-shaped grains are about 20 $40 \mathrm{~nm}$ in width and 100-200 nm in length. In contrast, not only $\mathrm{MgB}_{2}$ platelets but also unreacted B spheres, as well as voids, are observed in the transition region (Fig. 3(b)). This feature, similar to Fig. 2(d), demonstrates the microstructural transformation from B to $\mathrm{MgB}_{2}$. 


\subsection{Kinetic analysis of $\mathrm{MgB}_{2}$ layer formation in AIMI wires}

Microstructural analysis provides a useful starting point for analyzing the mechanism of $\mathrm{MgB}_{2}$ layer growth in AIMI wires. Fig. 4 schematically depicts it as a two-stage process. In Stage-I, heat treatment of the AIMI-processed precursor wire leaves a $\mathrm{Mg}$-depleted core surrounded by a thin cylinder of almost fully dense $\mathrm{MgB}_{2}$ produced by the initial rapid infiltration of liquid $\mathrm{Mg}$. Because of the abundance of $\mathrm{Mg}$, Stage-I is a "reaction-controlled" process. In Stage-II, reaction of the B remaining outside this cylinder requires the diffusion of $\mathrm{Mg}$ through the dense $\mathrm{MgB}_{2}$ inner layer. Due to a dearth of $\mathrm{Mg}$, Stage-II proceeds very slowly and is mainly "diffusion-controlled". In what follows a kinetic model is developed to describe the two-stage process.

3.2.1. Stage-I, dense $\mathbf{M g B}_{\mathbf{2}}$ layer formation-Stage-I is the reactive infiltration of liquid $\mathrm{Mg}$ into a porous B compact. The porous B provides a capillary network to encourage liquid $\mathrm{Mg}$ infiltration. As infiltration occurs, $\mathrm{Mg}$ is reacting with $\mathrm{B}$ at the same time, forming $\mathrm{MgB}_{2}$. Since the molar volume of $\mathrm{MgB}_{2}\left(17.46 \mathrm{~cm}^{3} \mathrm{~mol}^{-1}\right)$ is three times larger than that of $\mathrm{B}\left(4.59 \mathrm{~cm}^{3} \mathrm{~mol}^{-1}\right)$ [12], the interstitial voids between the initial $\mathrm{B}$ particles are gradually filled as liquid $\mathrm{Mg}$ continues to infiltrate. The depth of the infiltration grows with time, and during this time the $\mathrm{Mg}$ is in reaction with B powder all along the infiltration path. Eventually an $\mathrm{MgB}_{2}$ layer with almost $100 \%$ density is formed starting close to the surface of the prior $\mathrm{Mg}$ rod and extending all along the infiltration path. In short, during reactive infiltration the particles expand and eventually block the paths to further infiltration, resulting after time $t_{0}$ in a dense $\mathrm{MgB}_{2}$ layer of thickness $x_{0}$. There are two components to $t_{0}$. First there is the time $t_{\mathrm{p}}=x_{\mathrm{p}}{ }^{2} / D_{\mathrm{p}}$ needed to allow $\mathrm{Mg}$ to fully diffuse into the individual $\mathrm{B}$ particles of characteristic size $x_{\mathrm{p}}$, where $D_{\mathrm{p}}$ is the diffusion coefficient for $\mathrm{Mg}$ in $\mathrm{B}$. To be added to this is the time $t_{\text {form }}$ needed to complete the $\mathrm{Mg}+\mathrm{B} \rightarrow \mathrm{MgB}_{2}$ reaction.

In calculating $t_{\text {form }}$ we start by taking $X$ as the powder packing fraction in the B preform. Then according to the stereology [23], for randomly packed powders, the area fraction of $\mathrm{B}$ occupying the $\mathrm{Mg} / \mathrm{B}$ interface is also $X$. The value of $X$ typically varies around $64 \%$ for systems composed of randomly close-packed spheres, such as B powders in the as-drawn $\mathrm{MgB}_{2}$ precursor wire. According to previous analysis [12,18], a complete reaction of $\mathrm{B}$ powders with $X \sim 64 \%$ happens to result in the formation of fully dense $\mathrm{MgB}_{2}$. Therefore, in order for the completion of Stage-I, B powders close to the prior $\mathrm{Mg} / \mathrm{B}$ interface have to be totally reacted into $\mathrm{MgB}_{2}$. If $A_{\mathrm{SC}}$ is the area of the $\mathrm{Mg} / \mathrm{B}$ interface then the area of precursor B powder covering the interface is $A_{\mathrm{SC}} X$. Thus the amount of $\mathrm{B}$ along the $\mathrm{Mg} / \mathrm{B}$ interface is

$$
n_{\mathrm{B}}=\frac{A_{\mathrm{SC}} X}{N_{\mathrm{B}}} \quad(\mathrm{mol})
$$

where $N_{\mathrm{B}}$ is the molar area for B $\left(2.33 \times 10^{4} \mathrm{~m}^{2} \mathrm{~mol}^{-1}\right)$. Similar to molar volume in the three- dimensional system, the concept of molar area is introduced to quantify the concentration of B along the two-dimensional interface [24]. An estimation of $N_{\mathrm{B}}$ is provided in the appendix. 
$\mathrm{MgB}_{2}$ reaction is completed along the $\mathrm{Mg} / \mathrm{B}$ interface in time $t_{\text {form }}$ at an $\mathrm{MgB}_{2}$ formation rate form MB S

$$
J_{\text {form }}=k_{\mathrm{MB}} C_{\mathrm{S}} \quad\left(\mathrm{mol} \mathrm{m}^{-2} \mathrm{~s}^{-1}\right)
$$

where $C_{\mathrm{S}}$ is the concentration of $\mathrm{Mg}$ at the interface and $k_{\mathrm{MB}}$ is the rate constant $\left(\mathrm{m} \mathrm{s}^{-1}\right)$ for the chemical reaction $\mathrm{Mg}+\mathrm{B} \rightarrow \mathrm{MgB}_{2}$. According to chemical kinetics, $k_{\mathrm{MB}}$ only depends on temperature and reaction activation energy such that $k_{\mathrm{MB}}=k_{\mathrm{MB}}{ }^{*} \exp \left(Q_{\mathrm{MB}} / R T\right)$, in which $k_{\mathrm{MB}}{ }^{*}$ is the reaction rate constant at standard conditions and $Q_{\mathrm{MB}}$ is the activation energy for $\mathrm{MgB}_{2}$ formation. The amount of $\mathrm{MgB}_{2}$ formed at the $\mathrm{Mg} / \mathrm{B}$ interface is therefore

$$
n_{\mathrm{B}}=J_{\text {form }} \cdot t_{\text {form }} \cdot A_{\mathrm{SC}} \cdot \quad(\mathrm{mol})
$$

Upon combining Equations 1, 2 and 3 we find

$$
t_{\text {form }}=\frac{X}{k_{\mathrm{MB}} C_{\mathrm{S}} N_{\mathrm{B}}} .
$$

Thus the total time for Stage-I is

$$
t_{0}=t_{\text {form }}+t_{\mathrm{p}}=\frac{X}{k_{\mathrm{MB}} C_{\mathrm{S}} N_{\mathrm{B}}}+\frac{x_{\mathrm{p}}^{2}}{D_{\mathrm{p}}} .
$$

According to the Washburn model for liquid metal infiltration into porous media [25], the infiltration depth of liquid $\mathrm{Mg}$ into $\mathrm{B}$ is

$$
x_{0}=\left(\frac{r \gamma \cos \theta}{2 \eta}\right)^{1 / 2}\left(t_{0}\right)^{1 / 2} \quad(\mathrm{~m})
$$

where $r, \gamma, \theta$, and $\eta$ are effective pore radius, surface tension, wetting angle between liquid $\mathrm{Mg}$ and $\mathrm{B}$, and viscosity, respectively. It is noted that the Washburn model assumes the capillary effect plays the dominant role during the infiltration process. There are a few other factors which possibly contribute to liquid $\mathrm{Mg}$ infiltration into $\mathrm{B}$, such as the gravity of liquid $\mathrm{Mg}$, the pressure of the surrounding space above the liquid $\mathrm{Mg}$ [25] and the negative pressure created due to the volume shrinkage during $\mathrm{MgB}_{2}$ formation [15]. Thus, it may require a slight modification in Equation 6 when considering these factors [25]. But $x_{0}$ should still follow the general relationship of the above expression.

Combining Equations 5 and 6 we find an expression for the $\mathrm{MgB}_{2}$ layer thickness, $x_{0}$, when Stage-I is accomplished 


$$
x_{0}=\left(\frac{r \gamma \cos \theta}{2 \eta}\right)^{1 / 2}\left(\frac{X}{k_{\mathrm{MB}} C_{\mathrm{S}} N_{\mathrm{B}}}+\frac{x_{\mathrm{p}}^{2}}{D_{\mathrm{p}}}\right)^{1 / 2}
$$

Equation 7 shows that $x_{0}$ is affected by many parameters including the preform packing density $(X)$, the average pore size $(r)$, the $\mathrm{Mg}+\mathrm{B} \rightarrow \mathrm{MgB}_{2}$ reaction rate $\left(k_{\mathrm{MB}}\right)$ and, very importantly, the B particle size $\left(x_{\mathrm{p}}\right)$. The first term of Equation 5 represents a situation where just the instrinsic $\mathrm{Mg}+\mathrm{B}$ reaction (very local) is limiting, the second where the diffusion into the $\mathrm{B}$ particle is the controlling factor for setting the time for the infiltration process. In practice, as demonstrated in our later discussion, this latter term is dominant, such that Equation 7 can be approximated with the second term only.

3.2.2. Stage-II, prolonged heat treatment-After the completion of Stage-I all capillaries for infiltration are blocked. Further reaction requires $\mathrm{Mg}$ to diffuse through a dense $\mathrm{MgB}_{2}$ layer, a process of similar to the "Si thermal oxidation process" discussed by Deal and Grove [26]. With a $\mathrm{Mg}$ concentration at the initial $\mathrm{Mg} / \mathrm{B}$ interface of $C_{\mathrm{S}}$ dropping to $C_{\mathrm{i}}$ at the $\mathrm{MgB}_{2} / \mathrm{B}$ interface the diffusion flux through the dense layer of thickness $x_{0}$ is

$$
J_{\text {diff }}=\frac{D_{\mathrm{II}}\left(C_{\mathrm{S}}-C_{\mathrm{i}}\right)}{x_{0}} \quad\left(\mathrm{~mol} \mathrm{~m}^{-2} \mathrm{~s}^{-1}\right)
$$

in which $D_{\mathrm{II}}$ is the diffusion coefficient for $\mathrm{Mg}$ through $\mathrm{MgB}_{2}$.

This is equal to the rate of $\mathrm{MgB}_{2}$ formation starting at the $\mathrm{MgB}_{2} / \mathrm{B}$ interface:

$$
J_{\text {form }}=k_{\mathrm{MB}} C_{\mathrm{i}} . \quad\left(\mathrm{mol} \mathrm{m}{ }^{-2} \mathrm{~s}^{-1}\right)
$$

Since $J_{\text {diff }}$ must equal $J_{\text {form }}$ for mass equilibrium, we can eliminate $C_{\mathrm{i}}$ between Equations

$$
J_{\mathrm{diff}}=\frac{D_{\mathrm{II}} k_{\mathrm{MB}} C_{\mathrm{S}}}{k_{\mathrm{MB}} x_{0}+D_{\mathrm{II}}} . \quad\left(\mathrm{mol} \mathrm{m}^{-2} \mathrm{~s}^{-1}\right)
$$

After inserting $N_{\mathrm{v}}\left(\mathrm{mol} \mathrm{m}^{-3}\right)$, the amount of $\mathrm{Mg}$ needed to produce unit volume of $\mathrm{MgB}_{2}$, the layer growth rate can be written

$$
\frac{d x_{0}}{d t}=\frac{J_{\mathrm{diff}}}{N_{\mathrm{v}}}=\frac{D_{\mathrm{II}} k_{\mathrm{MB}}}{k_{\mathrm{MB}} x_{0}+D_{\mathrm{II}}} \cdot \frac{C_{\mathrm{S}}}{N_{\mathrm{v}}} . \quad\left(\mathrm{m} \mathrm{s}^{-1}\right)
$$

Then since Stage-II is a diffusion-controlled process, such that $k_{\mathrm{MB}} x_{0} \gg D_{\mathrm{II}}$, Equation 11 reduces to

$$
\frac{d x_{0}}{d t}=\frac{D_{\mathrm{II}} C_{\mathrm{S}}}{N_{\mathrm{v}}} \cdot \frac{1}{x_{0}} \quad\left(\mathrm{~m} \mathrm{~s}^{-1}\right)
$$

the solution to which is 


$$
x_{0}^{2}=\frac{2 D_{\mathrm{II}} C_{\mathrm{S}}}{N_{\mathrm{v}}} \cdot t+\text { const. } \quad\left(\mathrm{m}^{2}\right)
$$

The constant in Equation 13 can be evaluated by considering as a starting point for Stage-II the terminal conditions for Stage-I, viz $x_{0}$ and $t_{0}$, which for the present purpose we now write as $x_{0}^{*}$ and $t_{0}^{*}$. After doing so we find

$$
x_{0}^{2}=\frac{2 D_{\mathrm{II}} C_{\mathrm{S}}}{N_{\mathrm{v}}} \cdot\left(t-t_{0}^{*}\right)+\left(x_{0}^{*}\right)^{2} \cdot\left(\mathrm{m}^{2}\right)
$$

\subsection{Discussion}

In order to compare the Stage-I and Stage-II layer thicknesses we need to insert numerical values into Equation 14: (i) the diffusion coefficient $D_{\mathrm{II}}=10^{-17} \mathrm{~m}^{2} \mathrm{~s}^{-1}$ [27], (ii) the molar volume of liquid $\mathrm{Mg}, C_{\mathrm{S}}=6.52 \times 10^{4} \mathrm{~mol} \mathrm{~m}^{-3}$, and (iii) the amount of $\mathrm{Mg}$ per m$^{3} \mathrm{of} \mathrm{MgB}_{2}$, $N_{\mathrm{v}}=5.73 \times 10^{4} \mathrm{~mol} \mathrm{~m}^{-3}$. Equation 14 then becomes

$$
x_{0}^{2}=2.28 \times 10^{-5}\left(t-t_{0}^{*}\right)+\left(x_{0}^{*}\right)^{2} . \quad\left(\mu \mathrm{m}^{2}\right)
$$

According to our previous experimental results [18], an AIMI wire acquired a Stage-I reaction layer thickness $\left(x_{0}{ }^{*}\right)$ of $50 \mu \mathrm{m}$ after $60 \mathrm{~min}$ at $675^{\circ} \mathrm{C}$. Suppose the heat treatment is extended into Stage-II for a further time, $t-t_{0}{ }^{*}=60 \mathrm{~min}$. After substituting these numbers into Equation 15 we find the new layer thickness, $x_{0}$, to be equal to $50.0008 \mu \mathrm{m}$, which represents no significant increase in $x_{0} *$ beyond the Stage-I value, in reasonable agreement with our previous report [18] and results by other groups [14]. In other words, the very small diffusivity of Mg through the dense Stage-I layer prevents a large additional increase in layer thickness. Only grain-boundary-induced increases in $D_{\text {II }}$ would lead to significant amounts of Stage-II $\mathrm{MgB}_{2}$. As a consequence, the $\mathrm{MgB}_{2}$ layer thickness for AIMI wires is nearly equal to the thickness of the $\mathrm{MgB}_{2}$ layer formed in Stage-I.

As shown in Equation 5, the time for completing Stage-I is the time needed for $\mathrm{Mg}$ to diffuse into the B particles, $t_{\mathrm{p}}$, plus the time for $\mathrm{MgB}_{2}$ formation, $t_{\text {form }}$. The $\mathrm{Mg}+\mathrm{B} \rightarrow \mathrm{MgB}_{2}$ reaction rate $k_{\mathrm{MB}}$ at $675{ }^{\circ} \mathrm{C}$ is estimated to be about $10^{-10} \mathrm{~m} \mathrm{~s}^{-1}[27,28]$. Hence $t_{\text {form }}$, calculated from Equation 4 using $X=0.64, N_{\mathrm{B}}=2.33 \times 10^{4} \mathrm{~m}^{2} \mathrm{~mol}^{-1}$, and $C_{\mathrm{S}}=6.52 \times 10^{4}$ mol m${ }^{-3}$, amounts to $5 \mathrm{~s}$, a fairly short time. On the other hand the time for the $\mathrm{Mg}$ to diffuse into the largest B particles (i.e. $x_{\mathrm{p}}=120 \mathrm{~nm}$ and $D_{\mathrm{p}}=8 \times 10^{-18} \mathrm{~m}^{2} \mathrm{~s}^{-1}$ ) [29], $t_{\mathrm{p}}$, is about 48 $\min$. This is much longer than the formation time, $t_{\text {form }}$, and indeed close to a Stage-I experimental result [18]. The comparison between $t_{\text {form }}$ and $t_{\mathrm{p}}$ indicates that the time for Stage-I is dominated by $t_{\mathrm{p}}$-that required for $\mathrm{Mg}$ to fully diffuse into B particles. By manipulating the $\mathrm{B}$ particle size or $\mathrm{Mg}$ diffusion rate into $\mathrm{B}$, it is possible to extend the time for dense $\mathrm{MgB}_{2}$ layer formation, thus broadening the thickness of $\mathrm{MgB}_{2}$ layer. In this way, Giunchi et al. were able to produce large dense $\mathrm{MgB}_{2}$ objects ("manufacts") from crystalline B ground to sizes of 40-180- $\mu \mathrm{m}$ albeit at the expense of $J_{\mathrm{c}}(B)$ which decreased as $x_{\mathrm{p}}$ increased from $1 \mu \mathrm{m} \rightarrow 40 \mu \mathrm{m} \rightarrow 100 \mu \mathrm{m} \rightarrow 180 \mu \mathrm{m}[30,31]$. 
Besides reaction time, other factors like average pore radius also affect the $\mathrm{MgB}_{2}$ layer thickness in AIMI wires. Large pores usually provide wide capillaries, thus facilitating the infiltration. Fig. 5 demonstrates the effect of pressing on the $\mathrm{MgB}_{2}$ layer thickness. Pressing densifies the $\mathrm{B}$ preform, reduces the pore size within the precursor layer, and suppresses the infiltration during $\mathrm{MgB}_{2}$ layer formation. As shown in Fig. 5, the $\mathrm{MgB}_{2}$ layer thickness drops from 30-40 $\mu \mathrm{m}$ for the unpressed AIMI wire to less than $15 \mu \mathrm{m}$ for the pressed specimen. According to Equation 7, the thickness $x_{0}$ also involves the surface tension and viscosity of liquid $\mathrm{Mg}$, and the wetting angle between liquid $\mathrm{Mg}$ and $\mathrm{B}$. At $675^{\circ} \mathrm{C}$, the surface tension of liquid $\mathrm{Mg}$ is about $0.563 \mathrm{~N} \mathrm{~m}^{-1}$, and its viscosity is $1.119-1.147 \mathrm{mPa} \cdot \mathrm{s}$ [32]. It is reported that liquid $\mathrm{Mg}$ has very poor wettability on nanosized commercial B [31]. But unfortunately, no record has been found regarding the numerical value of the $\mathrm{Mg}-\mathrm{B}$ wetting angle. Once the wetting angle becomes known, we will be able to predict $x_{0} *$ based on the kinetic model above. In addition, according to Equation 7, we can see that efforts to improve the wettability or $\mathrm{Mg}$ surface tension are likely to contribute to an increase in the $\mathrm{MgB}_{2}$ layer thickness - a possible direction for future wire development.

Last to be discussed is the effect of $\mathrm{C}$ dopant concentration. In a recent paper we have reported on the suppression of the $\mathrm{MgB}_{2}$ layer thickness as a result of $\mathrm{C}$ doping [19]. DeFouw et al. [27] studied the $\mathrm{MgB}_{2}$ reaction activation energies, $Q_{\mathrm{MB}}$, for various types of B. For undoped plasma-synthesized boron $Q_{\mathrm{MB}}$ is $108 \mathrm{~kJ} \mathrm{~mol}^{-1}$, and for C-doped plasmasynthesized $\mathrm{B}$ it is $70 \mathrm{~kJ} \mathrm{~mol}^{-1}$. So at a given reaction temperature, C-doped AIMI wires which react faster than undoped ones (i.e. larger $k_{\mathrm{MB}}$ ) exhibit a shorter time for dense $\mathrm{MgB}_{2}$ layer formation. Furthermore $\mathrm{C}$ doping generates a higher density of defects in B powders [5], so $\mathrm{Mg}$ diffusion into $\mathrm{B}$ speeds up and $t_{\mathrm{p}}$ decreases accordingly. Both effects combine to reduce the $\mathrm{MgB}_{2}$ layer thickness for C-doped AIMI wires.

\section{Conclusions}

A careful SEM and TEM study of microstructural evolution indicates a two-stage mechanism for $\mathrm{MgB}_{2}$ layer formation in AIMI-processed $\mathrm{MgB}_{2}$ wires. Our kinetic model and the accompanying discussions reveal that the final $\mathrm{MgB}_{2}$ layer thickness is mainly governed by the thickness of $\mathrm{MgB}_{2}$ formed during the first stage. The final thickness of the $\mathrm{MgB}_{2}$ reaction layer is shown to depend not only on reaction time but also on B particle size, pore size in the preform, wetting angle and reaction activation. In general, the reaction layer will increase rapidly until it reaches a depth $x_{0}$, after which grows very slowly, such that $x_{0}$ can be defined as a "saturation reaction depth". It can be shown that $x_{0}$ is linearly dependent on B powder size, proportional to the square root of the radius of the porosity, and inversely dependent on the reaction rate of the local $\mathrm{MgB}_{2}$ formation reaction The kinetic analysis together with the expression for $\mathrm{MgB}_{2}$ layer thickness provide valuable tools for further optimization of the already high-performance AIMI-processed $\mathrm{MgB}_{2}$ superconductors.

\section{Acknowledgments}

This work was supported by NASA under SBIR contract NNX14CC11C and NIH, National Institute of Biomedical Imaging and Bioengineering, under R01EB018363. The authors thank Dr. G. Giunchi (Materials Science Consultant, Edison S.p.A. (retired)) and Dr. S. Dregia (The Ohio State University) for their helpful discussions. 


\section{References}

1. Larbalestier D, Gurevich A, Feldmann DM, Polyanskii A. High- $T_{c}$ superconducting materials for electric power applications. Nature. 2001; 414:368-377. [PubMed: 11713544]

2. Dou SX, Soltanian S, Horvat J, Wang XL, Zhou SH, Ionescu M, Liu HK, Munroe P, Tomsic M. Enhancement of the critical current density and flux pinning of $\mathrm{MgB}_{2}$ superconductor by nanoparticle SiC doping. Appl Phys Lett. 2002; 81:3419-3421.

3. Flükiger R, Hossain MS, Senatore C. Strong enhancement of $\mathrm{J}_{\mathrm{c}}$ and $\mathrm{B}_{\text {irr }}$ in binary in situ $\mathrm{MgB}_{2}$ wires after cold high pressure densification. Supercond Sci Technol. 2009; 22:085002.

4. Herrmann M, Haessler W, Rodig C, Gruner W, Holzapfel B, Schultz L. Touching the properties of NbTi by carbon doped tapes with mechanically alloyed $\mathrm{MgB}_{2}$. Appl Phys Lett. 2007; 91:082507.

5. Kim JH, Oh S, Kumakura H, Matsumoto A, Heo YU, Song KS, Kang YM, Maeda M, Rindfleisch M, Tomsic M, Choi S, Dou SX. Tailored materials for high-performance $\mathrm{MgB}_{2}$ wire. Adv Mater. 2011; 23:4942-4946. [PubMed: 21956864]

6. Li GZ, Sumption MD, Rindfleisch M, Thong CJ, Tomsic MJ, Collings EW. Enhanced higher temperature (20-30 K) transport properties and irreversibility field in nano- $\mathrm{Dy}_{2} \mathrm{O}_{3}$ doped advanced internal $\mathrm{Mg}$ infiltration processed $\mathrm{MgB}_{2}$ composites. Appl Phys Lett. 2014; 105:112603.

7. Tomsic M, Rindfleisch M, Yue J, McFadden K, Doll D, Phillips J, Sumption MD, Bhatia M, Bohnenstiehl S, Collings EW. Development of magnesium diboride $\left(\mathrm{MgB}_{2}\right)$ wires and magnets using in situ strand fabrication method. Physica C. 2007; 456:203-208.

8. Braccini V, Nardelli D, Penco R, Grasso G. Development of ex situ processed $\mathrm{MgB}_{2}$ wires and their applications to magnets. Physica C. 2007; 456:209-217.

9. Lvovsky Y, Stautner EW, Zhang T. Novel technologies and configurations of superconducting magnets for MRI. Supercond Sci Technol. 2013; 26:093001.

10. Kalsi SS. Superconducting wind turbine generator employing $\mathrm{MgB}_{2}$ windings both on rotor and stator. IEEE Trans Appl Supercond. 2014; 24:5201907.

11. Rowell JM. The widely variable resistivity of $\mathrm{MgB}_{2}$ samples. Supercond Sci Technol. 2003; 16:R17-R27.

12. Collings EW, Sumption MD, Bhatia M, Susner MA, Bohnenstiehl SD. Prospects for improving the intrinsic and extrinsic properties of magnesium diboride superconducting strands. Supercond Sci Technol. 2008; 21:103001.

13. Li GZ, Yang Y, Susner MA, Sumption MD, Collings EW. Critical current densities and $n$-values of $\mathrm{MgB}_{2}$ strands over a wide range of temperatures and fields. Supercond Sci Technol. 2012; 25:025001.

14. Togano K, Hur J, Matsumoto A, Kumakura H. Microstructures and critical currents of single- and multi-filamentary $\mathrm{MgB}_{2}$ superconducting wires fabricated by an internal $\mathrm{Mg}$ diffusion process. Supercond Sci Technol. 2010; 23:085002.

15. Giunchi G, Ceresara S, Ripamonti G, Zenobio AD, Rossi S, Chiarelli S, Spadoni M, Wesche R, Bruzzone PL. High performance new $\mathrm{MgB}_{2}$ superconducting hollow wires. Supercond Sci Technol. 2003; 16:285-291.

16. Ye SJ, Song MH, Matsumoto A, Togano K, Takeguchi M, Ohmura T, Kumakura H. Highperformance $\mathrm{MgB}_{2}$ superconducting wires for use under liquid-helium-free conditions fabricated using an internal Mg diffusion process. Supercond Sci Technol. 2013; 26:125003.

17. Kumakura H. Development of high performance $\mathrm{MgB}_{2}$ tapes and wires. J Phys Soc Jpn. 2012; 81:011010.

18. Li GZ, Sumption MD, Susner MA, Yang Y, Reddy KM, Rindfleisch MA, Tomsic MJ, Thong CJ, Collings EW. The critical current density of advanced internal-Mg-diffusion-processed $\mathrm{MgB}_{2}$ wires. Supercond Sci Technol. 2012; 25:115023.

19. Li GZ, Sumption MD, Zwayer JB, Susner MA, Rindfleisch MA, Thong CJ, Tomsic MJ, Collings EW. Critical current density and current transfer length of multifilamentary $\mathrm{MgB}_{2}$ strands of various design. Supercond Sci Technol. 2013; 26:095007.

20. Li GZ, Zwayer JB, Kovacs CJ, Susner MA, Sumption MD, Rindfleisch M, Thong CJ, Tomsic M, Collings EW. Transport critical current densities and $n$-values of multifilamentary $\mathrm{MgB}_{2}$ wires at various temperatures and magnetic fields. IEEE Trans Appl Supercond. 2014; 24:6200105. 
21. Marzik JV, Lewis RC, Nickles MR, Finnemore DK, Yue J, Tomsic M, Rindfleisch M, Sumption MD. Plasma synthesized boron nano-sized powder for $\mathrm{MgB}_{2}$ wires. AIP Conf Proc. 2012; 1219:296-301.

22. Scott GD, Kilgour DM. The density of random close packing of spheres. J Phys D: Appl Phys. $1969 ; 2: 863-866$.

23. West, MJ. Basic Stereology for Biologists and Neuroscientists. 1. Cold Spring Harbor Laboratory Press; New York: 2012.

24. Jain DVS, Singh S, Gombar V. Calculation of molar area of a substance at the liquid/vapor interface from surface tension and engergy of evaporation. J Chem Soc Faraday Trans. 1976; 72:1694-1696.

25. Low, IM. Ceramic-Matrix Composites: Microstructure, Properties and Applications. 1. Woodhead Publishing; Cambridge, England: 2006.

26. Deal BE, Grove AS. General relationship for the thermal oxidation of silicon. J Appl Phys. 1965; 36:3770-3778.

27. DeFouw JD, Quintana JP, Dunand DC. In situ X-ray synchrotron diffraction study of $\mathrm{MgB}_{2}$ synthesis from elemental powders. Acta Mater. 2008; 56:1680-1688.

28. Kim HM, Yim SS, Kim KB, Moon SH, Kim YW, Kang DH. Growth kinetics of $\mathrm{MgB}_{2}$ layer and interfacial $\mathrm{MgO}$ layer during ex situ annealing of amorphous boron film. J Mater Res. 2004; 19:3081-3089.

29. DeFouw JD, Dunand DC. Mechanism and kinetics of $\mathrm{MgB}_{2}$ synthesis from boron fibers. Acta Mater. 2008; 56:5751-5763.

30. Giunchi G, Ginocchio S, Raineri S, Botta D, Gerbaldo R, Minetti B, Quarantiello R, Matrone A. High density $\mathrm{MgB}_{2}$ bulk materials of different grains size Supercurrents instability and losses in variable magnetic fields. IEEE Trans Appl Supercond. 2005; 15:3230-3233.

31. Giunchi G, Ripamonti G, Raineri S, Botta D, Gerbaldo R, Quarantiello R. Grain size effects on the superconducting properties of high density bulk $\mathrm{MgB}_{2}$. Supercond Sci Technol. 2004; 17:S583S588.

32. International Magnesium Association. [accessed: December, 2014] Physical Properties of Magnesium. http://www.intlmag.org/magnesiumbasics/physical.cfm

\section{Appendix}

Conversion of 3-dimensional molar volume of B into 2-dimensional molar area within a plane (i.e. surface or interface): Assume isotropic, homogenously distributed unit cells inside of a crystal. The volume for a B unit cell can be estimated by the 3-dimensional molar volume of $\mathrm{B}\left(4.59 \mathrm{~cm}^{3} \mathrm{~mol}^{-1}\right)$ divided by the Avogadro's number $\left(6.02 \times 10^{23} \mathrm{~mol}^{-1}\right)$. So the volume for a $B$ unit cell is $7.6 \times 10^{-24} \mathrm{~cm}^{3}$. Thus, the cross-sectional area for this unit cell is about $3.87 \times 10^{-16} \mathrm{~cm}^{2}$, resulting in a planar density of $\mathrm{MgB}_{2}$ unit cells equal to 2.58 $\times 10^{15} \mathrm{~cm}^{-2}$. Dividing Avogadro's number by the planar density, we get an estimation of $\mathrm{MgB}_{2}$ molar area to be $2.33 \times 10^{8} \mathrm{~cm}^{2} \mathrm{~mol}^{-1}$, i.e. $2.33 \times 10^{4} \mathrm{~m}^{2} \mathrm{~mol}^{-1}$. 

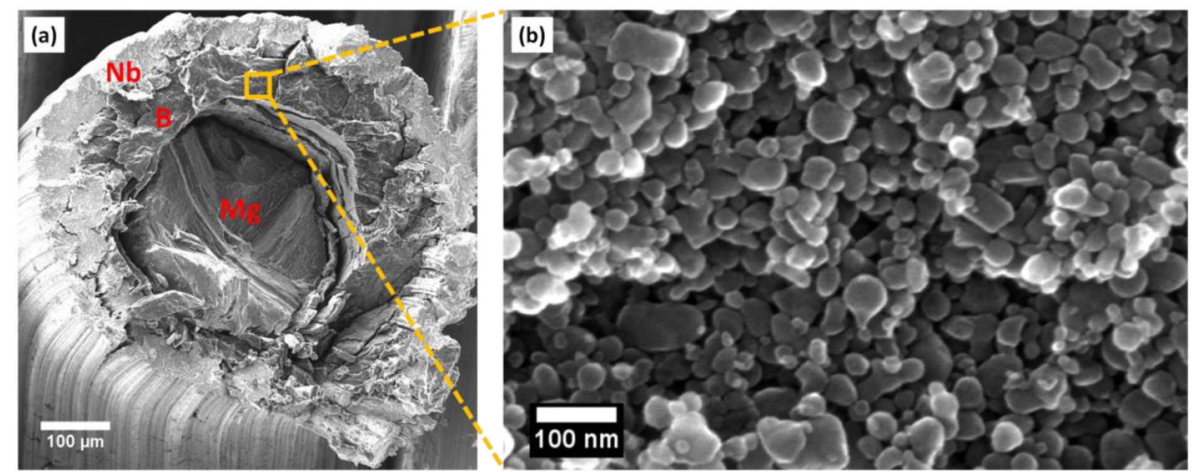

Fig. 1.

a) Fractural cross-sectional SEM image of the unreacted AIMI wire. The Monel ${ }^{\circ}$ sheath is etched away by nitric acid before observation. b) Enlarged SEM picture of the porous B preform which consists of nano-sized B particles and interstitial voids. 

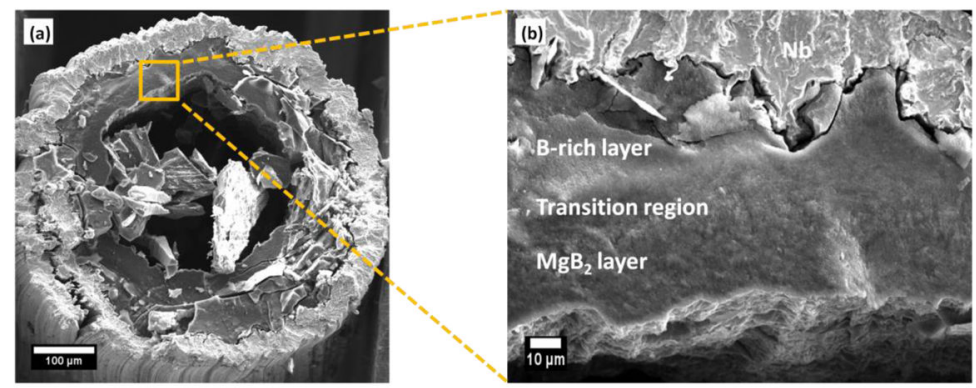

Dense $\mathrm{MgB}_{2}$ Layer

Transition Region
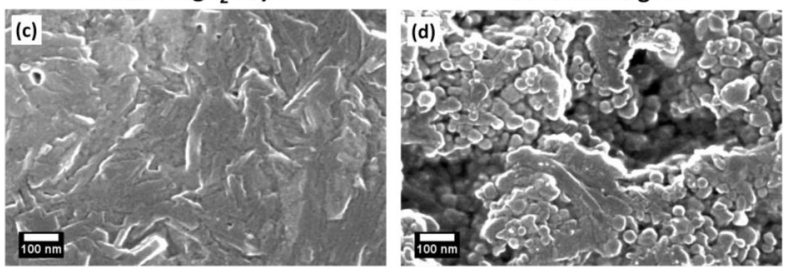

B-rich Layer

Fig. 2.

a,b) Fractural cross-sectional SEM images of the AIMI wire heat treated at $675^{\circ} \mathrm{C}$ for $1 \mathrm{~h}$. c-e) SEM images of the dense $\mathrm{MgB}_{2}$ layer, transition region and B-rich layer respectively. 

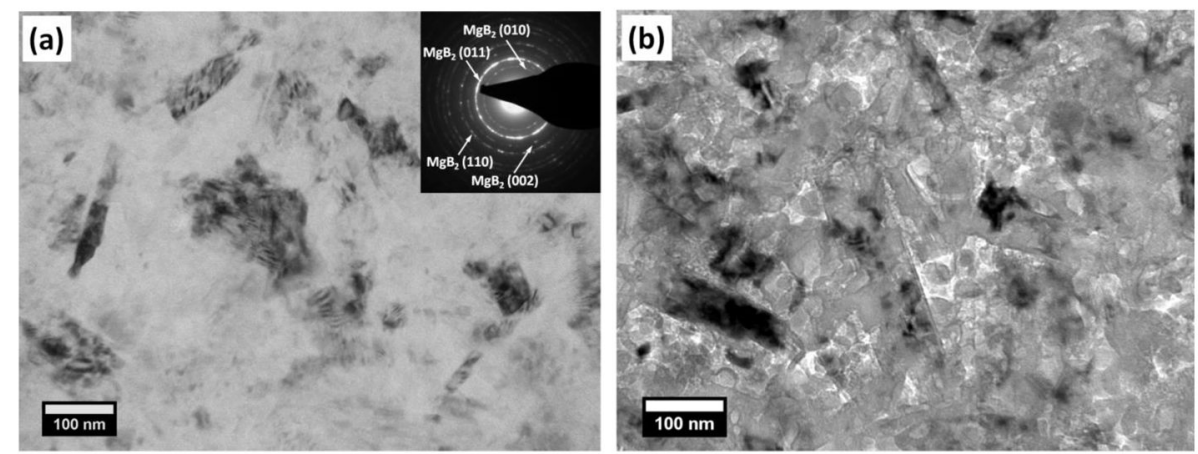

Fig. 3.

a) Bright field TEM image of a dense $\mathrm{MgB}_{2}$ layer. (insert: selective area diffraction image taken from the dense layer identifies the $\mathrm{MgB}_{2}$ phase. b) TEM image of the transition region consisting of $\mathrm{MgB}_{2}$ platelet grains, $\mathrm{B}$ spheres and voids. 


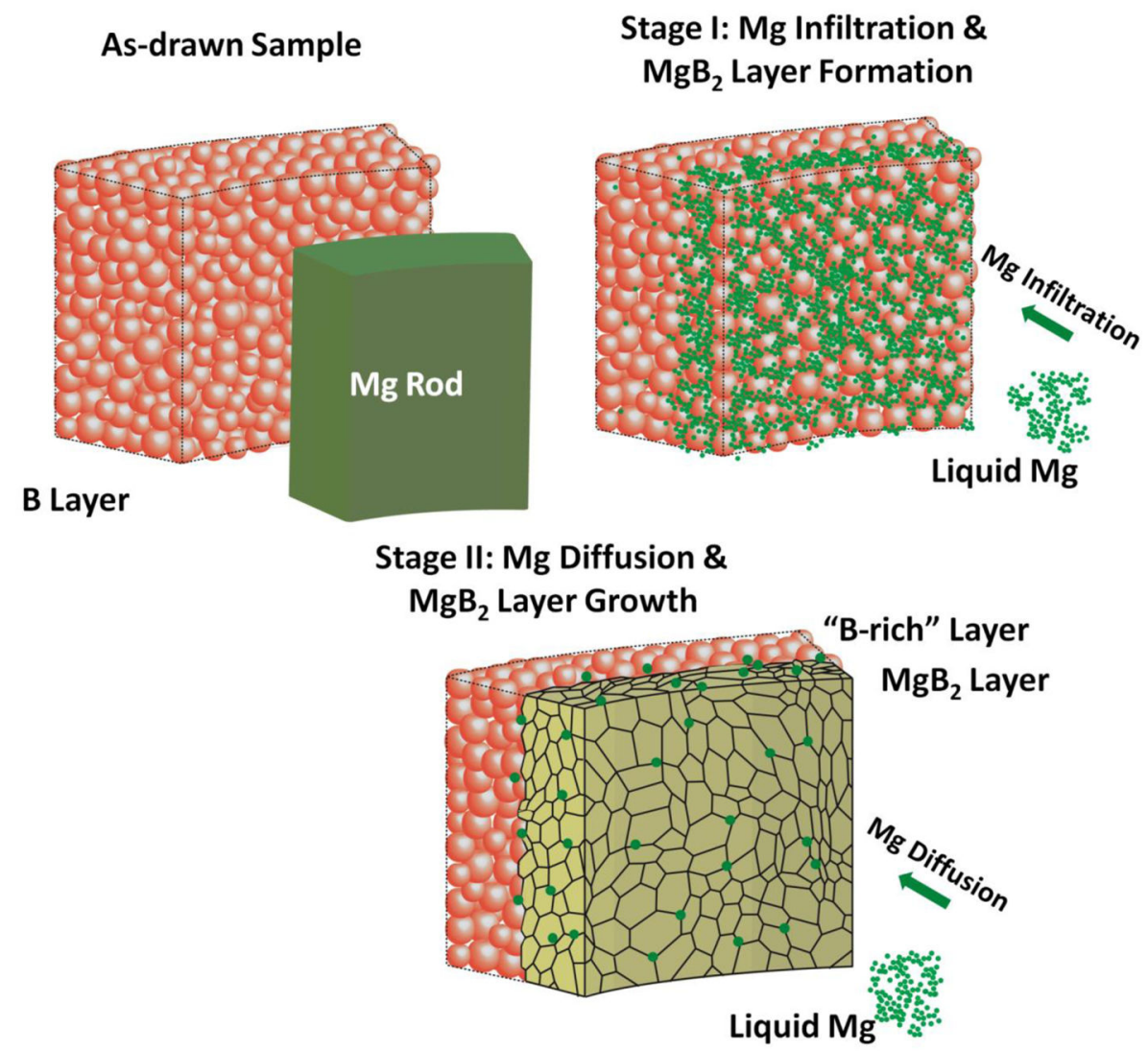

Fig. 4.

Schematic picture of the two-stage formation mechanism of the $\mathrm{MgB}_{2}$ layer in AIMI processed $\mathrm{MgB}_{2}$ wires. 

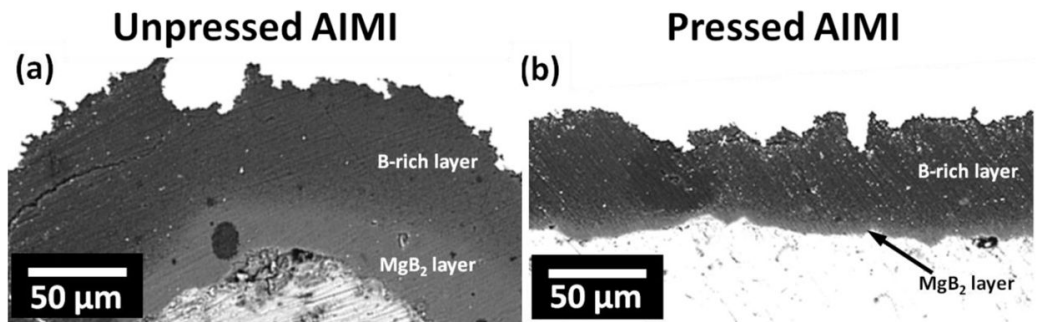

Fig. 5.

Back-scattered SEM images of a) an unpressed AIMI wire and b) a pressed AIMI wire. The image contrast is adjusted to clearly show the $\mathrm{MgB}_{2}$ layer and $\mathrm{B}$-rich layer. 